José Luis Villacañas Berlanga. Catedrático de Historia de la Filosofía en la Universidad Complutense de Madrid; director y fundador de la revista Res Publica y director de la revista Anales de Historia de la Filosofía; director de la Biblioteca Saavedra Fajardo de Pensamiento Político Hispánico. Sus principales temas de investigación son la historia de la filosofía y de las ideas políticas. Entre sus trabajos recientes se encuentran El lento aprendizaje de Podemos, Libros de la Catarata, Madrid, 2017; Freud lee el Quijote, La huerta grande, Madrid, 2017; Teología política imperial y comunidad de salvación cristiana, Editorial Trotta, Madrid, 2016; Populismo, La Huerta Grande, Madrid, 2015; e Historia del poder político en España, RBA, Barcelona, 2015.

Contacto: jlvillac@filos.ucm.es 


\title{
VERDAD Y RIGORISMO DE LA VERDAD ${ }^{1}$
}

Vol. 6, 2. Julio-Diciembre 2019 ISSN (online): 2539/2239 ISSN (print): 2389-8232 http://dx.doi.org/10.14718/SoftPower.2019.6.2.10

\author{
José Luis Villacañas Berlanga
}

Universidad Complutense de Madrid

\section{TRUTH AND RIGORISM OF TRUTH}

\section{Resumen}

En este artículo trataré de esbozar la evolución de la idea de verdad en la experiencia moderna. Al hacerlo, trataré con tres autores: Koselleck, Weber y Blumenberg. Analizaré la idea de verdad en estrecha relación con la cuestión de la política, es decir, con la cuestión de la res publica, de la formación de la comunidad, de la totalidad social, pero también con el espacio cada vez mayor de la técnica en nuestra condición actual.

\section{Palabras clave}

Rigorismo, síntoma, consuelo, entropía psíquica.

\section{Abstract}

In this paper, I'll try to sketch the evolution of the idea of truth in the modern experience. In so doing, I'll deal with three authors: Koselleck, Weber and Blumenberg. I'll take the idea of truth in a close connection with the question of politics, that's to say with the question of res publica, of the formation of community, with the social totality, but also with the growing space of technics in our present condition.

\section{Keywords}

Rigorism, Symptom, Comfort, Psychic Entropy.

1 Fecha de recepción: 1 de septiembre 2019; fecha de aceptación: 25 de septiembre 2019. El presente artículo es resultado de un proyecto de investigación desarrollado con el Dipartimento de Historia de la Filosofía en la Universidad Complutense de Madrid. 
Deseo ofrecer un ensayo apresurado de algunas posiciones sobre la evolución de la idea de verdad y nuestra condición presente. Nadie puede esperar de mí una exposición lógico-trascendental de la idea de verdad. Como se puede suponer, asumo los planteamientos básicos kantianos y procuro darles un sentido desde nuestra condición histórica como culminación, por ahora, de la experiencia moderna. Para ello, partiré, en el primer punto, de Reinhardt Koselleck, pues ha elaborado el cambio de sentido de la idea de verdad, aunque curiosamente no ha desplegado todas las consecuencias de tratarlo como un concepto político. En el segundo, haré referencia a que esta evolución viene marcada por la especialización como formación de comunidades particulares, sin pretensiones de totalidad, algo que afecta a la cuestión de la política, de la res publica y de la formación de una comunidad soberana. La forma fundamental de conexión de estas comunidades particulares de especialistas con el todo social, una vez cuestionada la forma de la política, ha sido la praxis técnica, y de este modo se puede desplegar una crítica a la idea de verdad que generó la línea de Hegel-Marx. Por ello, en el tercer punto propondré a Weber como otra forma de relacionar la idea de verdad con el todo social, ajena a la técnica, lo que implica en cierto modo reconectarla con la cuestión de la política. En cuarto lugar, propondré cómo, a pesar de todo, estas formas generan tensiones que hacen muy difícil que se abra camino una idea de verdad unitaria.

\section{1 \\ Koselleck}

En "Cambio de experiencia y cambio de método", ese artículo central de su libro Estratos del Tiempo (Koselleck, 2000, pp. 27-78), analiza Koselleck el cambio fundamental experimentado por la filosofía en medio de la evolución de la sociedad occidental. Se trata del cambio que podemos resumir de este modo: se pasó de la experiencia a la vivencia. Así establecido, este cambio representó el fracaso definitivo de Hegel y el paso a la romantización general de la sociedad mediante la democratización general del tipo de subjetividad que hasta el momento caracterizaba al genio, al héroe o, incluso, al espíritu del mundo. Koselleck lo caracteriza adicionalmente como el paso del activo investigar al percibir pasivo, que desde luego es un asunto paralelo a la diferencia hegeliana entre la verdad y la certeza. Aunque Hegel entendía que estas dos formas de conciencia eran expresiones de la autonomía del espíritu siempre seguro de sí mismo, comprendió que la certeza era la forma de relacionarse la intimidad 
con las señales propias de la recepción del Espíritu, tal y como había evolucionado el espíritu religioso reformado, mientras que la segunda, la verdad, era la forma en la que vive el espíritu que se sabe destinado a realizar su propia experiencia inmanente como Verweltlichung, mundanización o secularización, un proceso que, lejos de considerarse como una traición a las premisas teológicas, se vio como el intento fructífero de apreciar lo que existía de real en el fondo de ideas abstractas. De este modo, Hegel asoció de forma radical el proceso de verdad y el proceso de secularización, pues para él esa era la estructura de un Dios que no puede ni quiere ni debe abandonar el mundo. El mismo Hegel tuvo que luchar contra toda esa aspiración a considerar absoluto el contenido de la certeza y esa fue la índole de su combate contra el liberal Fries. Sin embargo, podemos decir que el siglo XIX, a través de la centralidad de la hermenéutica, primero de Schleiermacher y luego de Dilthey, y tras el derrumbe de la filosofía de Hegel tras 1848, vio el triunfo de la certeza entendida como vivencia cierta de sí, como Erlebnis. Fuese cual fuese el sistema de mediaciones que la búsqueda hermenéutica producía, el final del proceso siempre acababa en la autoconstatación de la propia intimidad. En realidad, fue este sentido de la vivencia consciente de sí completamente determinada por la apertura ante la vida lo que motivó la necesidad de la epojé husserliana, que reinició de nuevo el camino hacia una comprensión fuerte de la verdad como esencia.

Este cambio de la experiencia activa atravesada por la necesidad de implementar un método a la vivencia como apertura regida por la disponibilidad inspiró la nueva conciencia burguesa y dotó a sus elites de la identidad de una nueva forma aristocrática. Este cambio se registró de forma arquetípica en el arte y fecundó la literatura. No hay mejor ejemplo de esta nueva actitud que el de Hans Castorp, el héroe de la Montaña Mágica (1924), de Thomas Mann, que, instalado en la conciencia superior del Berghof de Davos, mira el mundo del llano con irónica distancia. Por supuesto que el personaje conoce ejercicios íntimos de la perseguir la vivencia destacada, pero en último extremo la matriz de la donación y de la gracia se abre paso en intimidad mediante una cierta sorpresa que se nos impone. La experiencia, el método, el trabajo de la realidad, los procesos de mundanización hegeliana, todo eso pasó a ser considerado como manifestaciones de la conciencia científico-natural, o de la conciencia material proletaria, mientras que esta apertura a la vivencia, con los peligros que encerraba, significaba más bien la configuración libre de la personalidad, la palabra mágica en la que se concentró todo el carisma de la nueva forma de ver el mundo. "Placet experiri", dice ese antihéroe de Thomas Mann, que necesita anclarse a la vida, para la que no está dotado, mediante 
continuos estímulos o vivencias capaces de llenar una vida vacía. "Experiri” es la forma pasiva de conducir una experiencia. Si tenemos que ponerle verbo al proceso, la transformación se dio entre experienciar y experimentar.

Este proceso puede considerarse en paralelo al que, según Simmel (2000), caracterizó el paso desde el siglo XVIII al siglo XIX, de los ideales de igualdad del gran siglo kantiano al ideal de libertad del siglo XIX, una evolución que podemos también describir como el tránsito de la universalización a la singularización y que de forma tan extraordinaria fue impulsado por Nietzsche. En todo caso, podemos decir que este proceso no se ha revertido. Y lo que es más importante: ni siquiera se ha pensado de forma clara lo que en realidad significaba en todos sus extremos. En todo caso, Koselleck no está interesado en lo que ha podido significar esta evolución para la cuestión política ni ha reflexionado sobre lo que había detrás de las aspiraciones de algunos pensadores de negar la premisa mayor de esta ordenación de la inteligencia, a saber, que las disciplinas que tienen que ver con el ser humano tienen una racionalidad esencialmente diferente de las disciplinas científica objetivas, o como diría finalmente Gadamer: que la verdad de las primeras no tiene posibilidad alguna de ser objetivada mediante un método. Esta ha sido la perspectiva triunfante en nuestras disciplinas mediante la imposición general de los estudios culturales, cuyos resultados siempre dependen del arsenal de asociaciones subjetivas que aporte el propio científico respecto de un tema dado. El capital científico de esta forma de entender cualquier disciplina cultural se alcanzaba así sobre la base de la excepcionalidad o la novedad, la rareza o la singularidad de las asociaciones. El autor más virtuoso en esta corriente no es otro que Slavoj Žižek.

\section{2 \\ Latour}

Uno de los primeros en investigar de forma material y concreta el significado de la experiencia y de la verdad en su sentido clásico ha sido Bruno Latour en su libro Nunca fuimos modernos (2007). La manera en que describe el proceso por el que se llegó a descubrir las propiedades elásticas del aire y se mejoró la bomba de vacío, impulsada por Robert Boyle, en el ambiente generado por el Colegio Invisible, nos indica que la ciencia moderna de la experiencia, en este caso la nueva química, fue un asunto compartido entre caballeros mutuamente obligados a la lealtad y la franqueza, a la sinceridad y la claridad, todas ellas virtudes sociales que, en el fondo, como mostró en su día Charles 
Webster, en su magnífico libro The Great Instauration (2002), recogió las formas secularizadas de la comunidad eclesial puritana. Es una pena que Latour no pusiera en relación este Colegio Invisible con el programa de los Hartlibianos, los seguidores de Samuel Hartlib, quienes a su vez estaban inspiradas por Francis Bacon (Lynch, 2017; Yates, 1972, pp. 220-247). Habría mostrado entonces la genealogía puritana de la ciencia experimental moderna (en una línea paralela a la de Max Weber para la economía y la de George Gellinek para la política). Pero, sobre todo, se habría podido preguntar por las relaciones entre la conformación de una idea de verdad, de una idea de derecho y de una de economía, y el tipo humano que configura no cada una de ellas, sino la base general de todas ella.

En este sentido, varias observaciones se imponen. La práctica activa de la verdad como experiencia metodológicamente guiada fue siempre un asunto comunitario y se forjó en la primera modernidad como hábito de conversación vinculada en el seno de grupos de caballeros relacionados entre sí previamente por su procedencia de comunidades de fe. Esta conexión de la comunidad de fe puritana con la comunidad de método y de experiencia es el gran logro teórico de lo herederos de Bacon, desde el Colegio Invisible a la Royal Society. La conexión entre superación de la certeza, búsqueda activa de la verdad y prácticas sociales comunes ya es perfectamente autoconsciente en Hegel, y los esfuerzos de Husserl o de Freud por garantizar la supervivencia de la escuela fenomenológica o psicoanalítica no constituyen sino la última consecuencia, una, por cierto, más o menos consciente, de la tensión entre esta aspiración que pasa por la comunidad y las bases cartesianas de los planteamientos modernos, que en el caso de Husserl pueden prescindir de esa comunidad desde la certeza del Cogito. De ahí la propuesta freudiana de la condición social de la formación de la forma yo y, más claramente, de la dimensión del superyó. Por el contrario, la emergencia de la experiencia como vivencia, que deja al singular entregado a las ilusiones de la soledad, se debe caracterizar como la desconexión del singular y sus intereses absolutos respecto de las estructuras comunitarias, ya completamente atravesadas por las dimensiones disciplinarias del Estado y capaces de producir un malestar en la cultura que ninguna comprensión compensatoria hegeliana pueden reducir.

Aunque el proceso por el que se disolvieron aquellas estructuras comunitarias es muy complejo desde el punto de vista histórico, podemos decir que viene caracterizado por el repliegue evolutivo de la comunidad eclesial hacia las tareas auxiliares de la disciplina estatal tal y como se conoció a partir de 1648 (Villacañas, 2010, pp. 11-38). Las comunidades particulares de fe se integraron en la comunidad estatal, que ahora las 
reconocía y a la que sirvieron de forma central con las mejoras técnicas que desplegaron las bases económicas de una razón de Estado previamente definida desde Botero en su ratio económica. Surgieron así todo tipo de utopías que vieron en esa alianza entre ciencia, Estado y economía la bases de una nueva edad de oro. En estas condiciones, en aquellas realidades sociales que no llegaron a la formación de esa Razón de Estado, basada en ese pacto, se conocieron otras formas de vida social no orientadas precisamente hacia el futuro, sino hacia el pasado, como fue el caso de la sociedad católica hispana. En los ámbitos reformados continentales no es difícil pensar que los intereses absolutos se dirigieran hacia la interioridad como objeto infinito otrora receptor de la gracia. Incapaces de entregarse a tareas mundanas de relevancia en un campo fragmentado por pequeños Estados plurales y mediocres, los talentos alemanes se replegaron en esa vida de la intimidad pendiente de sí misma y obtuvieron de ella el sentido irrenunciable de libertad que la noción de Espíritu ofrecía. Fueron los ancestros de lo que Hegel llamaría almas bellas y de los amantes de la vivencia. En todo caso, como vio Plessner de forma acertada, ni conocieron el sentido místico del Estado ni supieron reconciliar la vida religiosa con aspectos mundanos como la ciencia, a la que vieron como una dimensión fáustica y diabólica.

Verdad fue así la experiencia formadora de la sociedad burguesa atlántica y por eso, en cierto modo, llegó a su cima en la obra de Hegel, que la dotó de la legitimidad propia de ser la cumbre del Espíritu. Podemos asumir que la noción activa de verdad encontró defensores cualificados en aquellos pensadores que, como Marx, vieron con claridad hasta qué punto las certezas de la época burguesa construían formas fenoménicas porque en sí mismas no eran sino visiones naturalizadas. De este modo, recogiendo el legado hegeliano, Marx aceptó sus premisas a condiciones de que la historia no se detuviera en ellos. Así se esforzó por desplegar un discurso cuya finalidad fundamental era disolver las evidencias de lo que él llamaba sociedad burguesa, que había logrado ofrecer certezas a la totalidad social desde la configuración de una noción activa de verdad. Esta se caracterizó por traducir y ocultar el desarrollo histórico de la humanidad que la burguesía culminaba, fruto de la acción histórica del ser humano en la producción de su propia vida social a partir del despliegue de medios productivos, en una búsqueda de la naturaleza de las cosas. Así la sociedad burguesa se autopresentó como la sociedad natural. No pretendo recordar estas obviedades por recrearme en ellas. Simplemente deseo hacer pie en el mayor hallazgo anti-intuitivo de Marx. La sociedad, que parecía un continuo unitario, en el fondo estaba dividida en dos clases asimétricas con dos formas de representación y auto-representación completamente diferentes. Una vivía anclada 
en sus certezas como formas fenoménicas fetichizadas, mientras que otra, animada por la verdad de la evolución histórica abierta, estaba segura de su punto de vista científico y además podía disolver y explicar las formas falsas de la conciencia de la otra clase y traducirlas a su verdadera realidad. Solo porque había verdad, en cierto modo, algo podía ser ilusión, ideología. Sólo porque había historia, una clase podía aspirar a presentarse como la natural (Ruiz Sanjuán, 2019; Ramas De Miguel, 2018). Pues bien, esta consideración no logró triunfar finalmente porque, en su propio corazón teórico, renunciaba a algo decisivo: a la dimensión universalmente accesible de la verdad. En efecto, si bien la verdad de la época burguesa había sido fruto de su estructura comunitaria y de su práctica social, la verdad del marxismo no podía ser fruto de la experiencia compartida social. Este principio, conquistar la verdad al precio de la división sustancial de la sociedad en clases asimétricas, constituye la violación de un principio que en el fondo soporta cualquier teoría de la verdad: estar en condiciones de ser una nueva forma de recomposición general del mundo de la vida que unifica la sociedad. El marxismo de Marx exigía violar este principio. Carente de una forma específica y unívoca de producir una praxis inspirada en la teoría, la consecuencia fue su rebajamiento a lo que él mismo combatía: una comprensión fetichizada de ciertos elementos teóricos, que podían ser tan ideológicos como los que atacaba. De este modo, reducido a una ideología autorreferencial, se hundió como último muro capaz de defender la verdad en la sociedad actual.

Los intentos de Gramsci de configurar una idea de verdad capaz de ser compartida potencialmente por la totalidad de los estamentos sociales, y así fundar una nueva hegemonía, al final, reclamaban una filosofía de la historia que implicaba replantearse la teoría de la revolución. El marxismo no fue capaz de seguir esta estela. Tras refugiarse provisionalmente en una idea de ciencia tanto más formal cuanto menos seguida, la consecuencia fue la paradójica universalización de la ideología. De este modo, buena parte de la filosofía se reencontró con el principio de una subjetividad que no podía aspirar a otra cosa que a sus vivencias y certezas falsas, con lo que se aseguró de otro modo el triunfo radical de esa forma hermenéutica especialmente ligera que son los estudios culturales. Con ese triunfo, la sociedad de clases se derrumbó hasta convertirse, sencillamente, en sociedad de masas, donde cada uno hace su experiencia pasiva como vivencia, reservándose en ese flujo de vivencias la plena soberanía decisionista acerca de lo que es la verdad. Por supuesto, esta entrega al decisionismo de la verdad (que no es sino el bloqueo de todo camino activo, compartido y metódicamente conducido desde la certeza a la verdad) tiene como contrapartida la insignificancia de esas decisiones frente a la genuina verdad de eso que Heidegger caracterizó como Gestell, el verdadero 
trascendental de cualquier ver y comprender de todas esas decisiones, pero que resulta velado por la aparente soberanía de estas. Ese Gestell, ese conjunto desconocido, formidable, imponente de dispositivos, no necesita de los métodos de la vieja actividad de búsqueda de la verdad, y no prevé actividad alguna por nuestra parte para refinar nuestras certezas. Al contrario, nos anima a producirlas de forma continua como forma de mantenerse en su propio anonimato. Es de nuevo liberalismo: concede este ámbito pasivo de libertad a condición de ignorar la totalidad invisible en que se mueve.

3

\section{Weber}

Por supuesto, de todos los que resistieron este curso de las cosas, yo siempre invoco la figura de Max Weber, quien jamás aceptó algo parecido a la separación gadameriana de verdad y método, ni siquiera para aquellas disciplinas que reclamaron el aparente privilegio de carecer de él. En el fondo, el desmontaje de esta profunda asociación de la modernidad histórica entre verdad y método, con sus implicaciones de repetición, observación compartida, comunidad de formas de ver y apreciar, fue impulsado por una sociedad que entregó la defensa de valores absolutos trascendentes al prestigio de cleros especialistas, de mandarines filósofos o teólogos, herederos de las figuras de la Reforma ministerial, que creían tener asegurado su carisma como intérpretes autorizados de la tradición o que lucharon por conquistarlo como críticos radicales de la misma, como el caso de Nietzsche, pero que no pudieron detener de ningún modo la indisciplinada proliferación de las interpretaciones que da su versatilidad a los estudios culturales.

Max Weber escapó a este camino justo porque lo veía dominante en su medio social alemán. Y lo hizo porque reivindicó un sentido de la verdad todavía como práctica activa y metodológicamente asistida, pero de tal manera que no pedía el alto precio, contradictorio con esa práctica, de romper el mundo unitario de la vida; no defendió una teoría de la verdad al precio de hacerla de acceso imposible a una parte de la población, de escindir la sociedad en dos clases legitimadas en último extremo por el virtuosismo de la conquista exclusiva de la verdad en eso que se llamó teoría. Weber no rompió nunca la conexión entre la verdad y el mundo de la vida unitario porque no había verdad alguna sin referencia a un valor, y el valor no era sino la respuesta a una dolorosa fractura de las evidencias del mundo de la vida, experimentado por algún tipo de sufrimiento social. Sostenido por un agudo sentido de la pluralidad de los bienes y de los 
sufrimientos que muestra un mundo de la vida tan estable como frágil, su ciencia jamás se distancia de esta pluralidad consciente de intereses que encierra la noción de valor, y que tiene tan poco que ver con las pretendidas objetividades de una intuición esencial fenomenológica. Si recordamos este texto, nos damos cuenta de hasta qué punto Weber se aleja de la línea Dilthey-Gadamer, pero sobre todo de la consecuencia de esta entrega a la soberanía de la decisión que convierte la certeza en verdad y la verdad en mera certeza. El texto dice así:

\begin{abstract}
Es preciso romper la opaca uniformidad del vivenciar [Erleben] si queremos dar el primer paso hacia una genuina comprensión de nosotros mismos. Cuando se dice que cada vivencia [Erlebnis] es perfectamente cierta, es obvio que con ello se quiere decir que hemos tenido una vivencia. Pero de qué cosa hemos tenido un vivenciar [Erleben], esto es algo que puede ser accesible a la interpretación solo si se abandona el estadio de vivencia misma y se hace de lo vivido un objeto de juicio cuyo contenido, a su vez, no pueden ser vivido [erlebt] en su uniforme opacidad, sino que es construido como válido. [...] Hace referencia a la validez de los juicios, sean nuestros o ajenos. (Weber, 1992, p. 124)
\end{abstract}

En este texto, Weber hacía un llamamiento a diferencia la erlebt Einheit, y el pensar reflexivo sobre ella, que implicaba el reconocimiento de la validez. Pero para dotar de validez a un juicio se requería todo un proceso activo-reflexivo compartido que implicaba desde la formación de conceptos hasta la posibilidad de asentar la comprensión de una vivencia mediante su incorporación a procesos explicativos que incluían dimensiones de causación adecuada. Su tesis fundamental podría decir que no hay verdad sin que estemos en condiciones de incluir algún tipo adecuado de causación. En todo caso, entre Erleben y Erfahren hay una gran diferencia, hasta el punto de que se trata de dos procesos antitéticos. La primera era un vivenciar pasivo no elaborado lógicamente. El segundo siempre implicaba una lógica y una elaboración activa que podía ser descrita y discutida sobre su adecuación a fines y, por tanto, metodológicamente establecida.

Aunque es muy difícil identificar el sentido de la ciencia y de la verdad en Weber de un solo vistazo, al menos podemos reflexionar para ofrecer algunos detalles adicionales. Si recordamos, he hecho relación al problema del mundo de la vida. Esa categoría, ciertamente, guarda muchos parecidos con la noción de "imagen manifiesta" de Wilfrid Sellars (1979), que debería elaborar más, pues él también estaba interesado 
en vincular pasividad y actividad en la línea de Kant, pero sin asumir esta naturalidad de lo dado en la intuición. En principio, el asunto del mundo de la vida ha alcanzado relevancia en el presente a partir de la publicación de Hans Blumenberg (2013) sobre el tema y su proceso de distanciamiento de Husserl. Aquí no puedo detenerme mucho, pero sí decir que el mundo de la vida es aquel del que no se puede prescindir, pero en el que no se puede permanecer. Por supuesto, tenemos aquí un índice de la finitud humana. El ser humano no puede permanecer en su condición ni en aquello que mejora su condición. No puede permanecer en su indeterminación originaria, ni en los mundos de la vida que elabora para superarla. Esta es la estructura más profunda de su finitud. Con este concepto invocamos, sobre todo, un desajuste originario insuperable. Por mucho que el ajuste de vivencias esté realizado mediante el complejo mundo pre-predicativo husserliano, este siempre se rompe en su temporalidad básica y en sus retenciones y protensiones. Por supuesto, muchas de sus fracturas de expectativas se recomponen de forma mítica: se varía en las narraciones y en las historias que lo atraviesan. Debemos recordar que esta estructura mítica simbólica de todo mundo de la vida fue el legado de Cassirer a Sellars (Sellars, 2018). Esa era la base de la imposibilidad de naturalizar una ontología. Pero hay fracturas que llevan consigo un sufrimiento de tal índole que no hay a mano una variación del relato mítico para recomponerlo o, lo más probable, que los relatos recompuestos ya hayan agotado su capacidad de consuelo. Entonces, esa pérdida, ese sufrimiento, genera una reflexión, de la que se identifica un valor justo a través de la experiencia de una falta. Weber concedió prioridad al sufrimiento sobre el conocimiento y la conciencia de valor no es sino un derivado de aquél. Ahora bien, ese valor, conciencia de una pérdida de algo que estaba supuesto, implícito, asumido en la estructura estable del mundo de la vida, activa el recuerdo, y permite reactualizar latencias fruto de vivencias y de experiencias pasadas. Con ello se inicia la vida reflexiva que permite elaborar conceptos, formas de unir recuerdos, diversidad, etcétera.

Invoco aquí mi trabajo sobre la categoría de latencia para aclarar el punto decisivo: que todo sistema inteligente está atravesado por la latencia. Este es el elemento insuperablemente platónico de la filosofía. Sobre ella tiene funcionalidad la reflexión. Toda elaboración de la temporalidad tiene significado por esta referencia a valor, la clave de la comprensión de las ciencias sociales o ciencias de la cultura en Weber. Por lo tanto, todas ellas tienen como finalidad no romper con el mundo de la vida, sino recomponer sus pérdidas irreparables. Por eso no habla para una clase. Sigue teniendo vocación de universalidad, solo que relativa. Habla a los que se sienten concernidos 
por esa pérdida cristalizada en valor. Si las cartas de Goethe a la señorita Ulrike von Levetzow son relevantes es porque encierran un extraordinario significado para aquellos que han perdido o son conscientes de la fragilidad del sentido del amor. Las prestaciones de la elaboración de la interpretación de estas cartas revierten sobre el mundo de la vida y recompone sus fracturas. Pero para ello debe relacionar de alguna manera relevante las estructuras objetivas de la experiencia de Goethe con las estructuras objetivas del mundo del lector. De otro modo: debe disponer de alguna verdad, de alguna elaboración. Por supuesto, que esto siempre sucede de un modo u otro, pero el problema es que suceda de manera consciente y capaz de dar cuenta del proceder. De no ser así, estas interpretaciones no pueden sino ayudar a fracturar el mundo de la vida, a desajustarlo y a producir mayor dolor, anulando la posibilidad de que incorpore valor, de que pueda restituir las pérdidas.

Aunque soy muy consciente de lo mucho que hay que refinar, creo que cuando miramos las cosas desde esta perspectiva apreciamos una convergencia entre el programa de Weber y el de Freud. Por supuesto que ambos anclan en una aspiración de verdad. Lo importante es que ambos, discípulos de Nietzsche, a fin de cuentas, parten de que solo el sufrimiento nos pone en el camino de esta. Freud, como Weber, parte de los pequeños sufrimientos que interrumpen el mundo de la vida y para los que el que los padece no tiene relatos mitológicos sobre los que variar. Su respuesta es impulsar la reflexión hasta que el paciente realiza el relato mitológico singular adecuado a sí mismo, con el que avanzar a través del mundo de la vida con suficiente protección para controlar la irrupción de los síntomas. Por supuesto, esto es imposible de llevar a cabo sin una forma reflexiva metodológicamente orientada y ante la atenta observación del analista como garantía de adecuación metódica. La consecuencia es la producción de una verdad singular, sin la cual no veo posibilidad de impulsar el cuidado de sí. El resultado de este proceso de producción de verdad es fortalecer al paciente frente a las fragilidades del mundo de la vida, la irrupción de lo siniestro, la permanente posibilidad de la decepción y la culpa. El carácter complementario de Freud y Weber es que, mientras que Weber ofrece la posibilidad de obtener verdad acerca de acciones sociales particulares orientadas a diversos bienes frágiles o valores (ciencia, estética, política, economía, eros, religión), Freud ofrece todavía prestaciones más básicas sobre nuestro sentido libidinal y nuestro propio superyó, ideal del yo o yo ideal con el que componer la imagen narcisista secundaria capaz de unificar el sentido de todas estas esferas de acción. Esto es posible porque el nivel de reflexión antropológica metapsicológica de Freud es más básico que el nivel de antropología histórica de Weber. 


\section{4 \\ Blumenberg}

Ahora debemos ver los obstáculos que en la sociedad contemporánea se levantan frente a una teoría de la verdad integral. Para este análisis utilizaré libremente las reflexiones de Hans Blumenberg, para mí el filósofo más relevante de la segunda mitad del siglo XX. Uno de los últimos libros póstumos de Blumenberg tiene este curioso título Rigorismus der Wahrheit (2016). Editado por la prestigiosa editorial Suhrkamp, de Frankfurt, defiende la siguiente tesis: "Nada es menos seguro que la verdad quiera ser amada, pueda ser amada, deba ser amada”. Es una frase que causa extrañeza. Finalmente, Blumenberg es el analista de la revolución copernicana, de la legitimidad de la modernidad, de la legibilidad del mundo y, finalmente, de la descripción del ser humano. Ninguna de estas temáticas puede avanzar sin una teoría de la verdad. La impronta de su pensamiento, sin embargo, viene marcada por lo que podemos llamar una Ilustración consciente de su propia dificultad. Una de estas dificultades es el rigorismo de la verdad. Para empezar a comprender esta paradoja, tal y como yo la entiendo, hemos de recordar una tesis que analicé en mis Dificultades con la Ilustración (Villacañas, 2013). Hace referencia a lo que conocemos como "Ilustración considerada". Esta es aquella que no se deja llevar por el rigorismo de la verdad. Podemos decir que los dos autores a quienes Blumenberg acusa de rigorismo de la verdad, el Freud del Moisés y el origen de la religión monoteísta, por un lado, y la Arendt de Eichmann en Jerusalén, por el otro, son otros tantos representantes de la Ilustración desconsiderada. Y esta consiste en que irrumpe de tal manera que tiene efectos que destruyen las formas de consuelo humano que fortalecen el mundo de la vida. En el caso de Freud la escritura del Moisés fue el fruto de la desesperación, lo que le indujo a cambiar el sentido de sus propias investigaciones. Lo que es desconsiderado en la Ilustración que se entrega al rigorismo de la verdad son los consuelos del mundo de la vida. Se usa la verdad, no para asentarlo y recomponerlo, sino para agitarlo y desestructurarlo más. Así, Freud escribe su Moisés para demostrar que el fundador del pueblo de Israel no fue un israelita y que toda su tarea implicó un desprecio profundo por ese pueblo, sin considerar el hecho de que en 1939 esa verdad retiraba a un pueblo sufriente el sentido de sus ceremonias de consuelo. De la misma manera, el escrito de Arendt venía a decir que, sin la propia organización de los judíos a favor de la solución final, la eficacia del aparato nazi no habría sido tan alta. Esta culpabilización de los propios judíos en el Holocausto retiraba el consuelo de los supervivientes. 
¿Por qué ha mostrado Blumenberg la necesidad de limitar los efectos desestructurantes del rigorismo de la verdad en las ciencias que tienen que ver con el ser humano? Básicamente porque, muy buen lector de Freud, Blumenberg asume que la ciencia no cesa de darnos malas noticias. En suma, él no podría lanzar contra Einstein, a Darwin, o a Schrodinger el cargo de rigoristas de la verdad. La ciencia natural no forma parte de la Ilustración. Sirve a su propio fin y basta. Pero esa ciencia, como definió magistralmente Freud, no cesa de humillar al ser humano. La estructura de la revolución copernicana, que es la estructura de la modernidad, no es sino la acumulación de humillaciones a las que el ser humano responde con otras tantas formas de autoafirmación. Se comprenderá mal el sentido de la autoafirmación como lo que presta legitimidad a la modernidad, si no se repara en que la autoafirmación es tal porque supera una humillación cada vez más radical. De ahí procede la valentía: reacción contra la humillación. Pues bien, esa humillación desestabiliza todavía más el mundo de la vida, le retira todas sus evidencias, destruye todas sus estables facticidades a las que substituye por una insoportable contingencia que deja sin aliento, porque no nos ofrece las garantías de habitar en un cosmos eterno, sino en un proceso azaroso y abierto. Y la forma en que la ciencia se despliega en la técnica ha mostrado sus límites de estabilización del mundo de la vida, porque sin duda, primero, los costes del mantenimiento de la técnica destruyen la estabilidad de la Tierra como escenario general del mundo de la vida, y segundo, porque cada nuevo avance técnico genera efectos en nosotros que desestabiliza también nuestros hábitos, nuestras relaciones humanas básicas, nuestro sentido de lo sobreentendido, y nos conmina a una adaptación costosa. Así, la técnica destruye continuamente aspectos del mundo de la vida personal y social que además amenazan el sobreentendido básico, el que hace del ser humano un animal de la Tierra. Por supuesto que la técnica forja mundos de la vida técnicos, pero sus costos reflexivos son muy altos. Por mucho que miremos ansiosos a la ciencia en todos sus descubrimientos, porque pueden mejorar el tiempo de la vida del singular, comenzamos a preguntarnos si mejoran también el tiempo de la vida de la especie. En todo caso, el tiempo de deber que reclama el trabajo de la ciencia y de la técnica cada vez imponen más restricciones al tiempo de poder, lo que perturba la economía de la vida personal.

La ciencia reduce el campo de los consuelos. Si la técnica lo reduce todavía más, la Ilustración no puede asumir el rigorismo de la verdad dejando al ser humano sin los consuelos que han sobrevivido y están insertados en el mundo de la vida. Este círculo condiciona nuestra vida sin poder darle una forma. Miramos hacia la ciencia para encontrar soluciones, pero de esta mirada extraemos siempre decepciones. La ciencia 
técnica ha encontrado medios de superación del sufrimiento más eficaces en el corto plazo, pero no ofrece un horizonte de consuelo en el largo. Si aceptamos la antropología freudiana, la necesidad de consuelo se basa en la dificultad de dar respuesta a la pulsión de muerte. Esta dificultad determina que el principio de placer no esté en condiciones de dar los rodeos y retardos característicos y se entregue a su propia pulsionalidad sin equilibrios, por no hablar de los desarreglos de la propia pulsión de muerte carente de orden interno. Si todo síntoma en sentido freudiano es señal de sufrimiento, vivimos en la sociedad en que todos los síntomas se exponen, pues encuentran sólo alivio en su propia exposición. En suma, los síntomas son su propia forma de consuelo. Al reverberar y reflejarse unos en otros, se aplacan en su propia circulación. No producen un malestar que exija reflexión, puesto que se expanden en reflejos. Por lo demás, la experiencia del malestar ha cambiado: ya no se considera que el malestar se pueda recomponer mediante procesos reflexivos, porque en realidad procede de la existencia de los otros. El malestar en la cultura, que Freud cifró en las imposiciones que al aparato libidinal impone la civilización, ya no funciona así. El principio de placer no encuentra mayores obstáculos en la sociedad y eso es lo que Foucault ha caracterizado como la capacidad productora de libertad del neoliberalismo y su potencia biopolítica. El malestar en la cultura actual viene más bien caracterizado por la desproporción entre la libertad absoluta del principio de placer y la carencia de trabajo cultural sobre el principio de muerte, que sobrecarga pulsionalmente el principio de placer con dimensiones de aceleración que presentan todo el aspecto de caminos disolventes, formas de canalizar la pulsión de muerte desasrreglada. La aparente armonía del mercado, como lugar donde todas esas libertades ya pulsionales se realizan, es la otra cara de la exposición sintomática en las redes, donde todos los síntomas se exhiben reflejándose recíprocamente y de este modo justificándose y gozándose en su normalidad.

Desde Pascal, las malas noticias que traía la ciencia para el ser humano, al presentarnos un cosmos tenebroso e insondable en el que apenas somos como hormigas para un observador externo, se pretende compensar con una verdad propia del ser humano, aquella verdad que solo puede ser resultado del mirarse a sí mismo del ser humano, singular o como especie. Freud y Weber, cada uno en un campo, fueron las últimas de estas compensaciones, cuya finalidad última era contribuir a un orden de la pulsión de muerte. Sin embargo, en nuestra vida no solo hemos perdido el sentido de todas las compensaciones reales que antes gozamos, sino incluso la idea de que el ser humano necesita compensaciones. Esta situación es la que determina que no dispongamos de un estilo de vida, lo que en modo alguno es posible sin contar con un sentido de la verdad. 
Escindidos entre una ciencia que jamás nos brinda el sentido de una totalidad vital, una técnica que avanza siempre en el sentido del autismo pulsional y la autosuficiencia, y un mundo de la vida atravesado por la exposición libérrima de los síntomas, sin necesidad de verlos como señales de una verdad que espera ser conocida, el ser humano contemporáneo vive escindido entre un ansia de verdad acerca del mundo en el que pone todos sus anhelos y un rechazo de que él todavía tenga que responder a una verdad acerca de sí mismo. En suma, hemos olvidado que la verdad no es la respuesta a una necesidad humana, sino a varias.

Entre ellas, la necesidad de explorar el horizonte material para estabilizar el mundo de la vida de los asaltos de los imprevistos, pero también la necesidad de orientación en el horizonte temporal de la existencia en lo que tiene de humana, justo para lo mismo. Los grandes esfuerzos de Weber y de Freud fueron convergentes en la tarea de mostrar una verdad acerca del tiempo colectivo social y del tiempo personal singular, y por eso estuvieron a la altura de los grandes avances del conocimiento de las realidades materiales. El abandono de su programa de historia social y de historia singular nos ha llevado a la carencia de prácticas globales de verdad sobre nosotros, de tal modo que solo queda el mercado como institución que dice algo del fragmento de la verdad de lo que pulsionalmente somos. Pero el mercado no ofrece verdades que respondan a las necesidades de orientación ni pueden brindarnos cuidado de sí. Y por eso, carentes de una verdad sobre nosotros mismos, de la que se derive una respuesta a la orientación como grupos y como singulares, carentes por tanto de una solución a la pulsión de muerte, solo nos queda el consuelo de la exposición brutal del síntoma. Eso es lo que se ha llamado posverdad. Adónde nos lleve esta escalada de brutalidad no será nada nuevo. El ser humano ha conocido muchos momentos en los que carecía de un sentido de la verdad de sí mismo y no tenía a la mano consuelo alguno. Solo nos queda decir que no han sido momentos dichosos. Ignoramos cuál será la forma de la desgracia del futuro que vendrá. Pero como se dijo un día del Reino: "Ya está entre nosotros, aunque todavía no ha llegado".

\section{Referencias}

Blumenberg, H. (2013). Teoría del mundo de la vida. México: FCE. Blumenberg, H. (2016). Rigorismus der Wahrheit. Frankfurt: Suhrkamp. Koselleck, R. (2000). Zeitschichten, Studien zur Historik. Franfurt: Suhrkamp. 
Koselleck, R. (2001). Estratos de Tiempo. Barcelona, Buenos Aires: Editorial Paídos.

Latour, B. (2007). Nunca fuimos modernos. Ensayo de antropología simétrica. Buenos Aires: Siglo XXI.

Lynch, W. T. (2017). A Society of Bacanians? The Collective Development of bacon's Method in the Royal Society of London. En J. Robin Solomon, C. Gimelli Martin (Eds.), Francis Bacon and the Remodeling of the Early Modern Thought: Essays to Commemorate the Advancement of Learning (1605-2005) (pp. 173-202). Londres: Routledge.

Ramas De Miguel, C. (2018). Fetiche y Mistificación capitalista. La crítica de la economía política de Mar., Madrid: Siglo XXI.

Ruiz Sanjuán, C. (2019). Historia y sistema en Marx. Hacia una teoría crítica del capitalismo. Madrid: Siglo XXI.

Sellars, W. (1979). Naturalism and Ontology. Atascadero: Ridgeview Publishing Co.

Sellars, W. (2018). Kant's Transcendental Metaphysics: Sellar's Cassirer Lectures Notes and Other Essays. Atascadero: Ridgeview Pub.

Simmel, G. (2000). El individuo y la sociedad. Ensayos de crítica de la cultura. Barcelona: Península.

Villacañas, J. (2015). Foucault 1648. Res Publica, Revista de Historia de las Ideas políticas, 24, 11-38.

Villacañas, J. (2013). Dificultades con la Ilustración. Ensayos kantianos. Madrid: Verbum.

Weber, M. (1992). Sobre la irracionalidad de las ciencias sociales. Madrid: Tecnos.

Webster, Ch. (2002). The Great Instauration, Science, Medicine, Reform, 1626-1660. Londres: Peter Lang.

Yates, F. (1972). The Rosicrucian Enleigtenment. Londres: Routledge. 
